\title{
CARACTERÍSTICAS PRODUTIVAS DAS UPL'S E FATORES CONDICIONANTES DA QUALIDADE DO LEITE ATÉ A INDÚSTRIA NO TRIÂNGULO MINEIRO
}

Wallacy Augusto de Oliveira ${ }^{1}$, Maurício Scoton Igarasi², Marcos Nunes de Freitas ${ }^{3}$, Jonathan de Oliveira Gonçalves ${ }^{1}$, Lucas Vieira Silva ${ }^{4}$

\begin{abstract}
${ }^{1}$ Mestrando em Sanidade e Produção Animal nos Trópicos, Universidade de Uberaba (Uniube), Uberaba-MG, Brasil; 2ZZoot., D. Sc., Docente no curso de graduação em Medicina Veterinária e no Programa de Mestrado em Sanidade e

Produção Animal nos Trópicos da Universidade de Uberaba (Uniube), Uberaba-MG, Brasil;

${ }^{3}$ Méd. Vet., Universidade de Uberaba (Uniube), Uberaba-MG, Brasil;
\end{abstract}

${ }^{4}$ Eng. Agr., Instituto Federal do Sudeste de Minas Gerais - Campus Barbacena, Barbacena - MG, Brasil;

RESUMO: Objetivou-se com esse trabalho avaliar as características das Unidades Produtoras de Leite (UPL's) e demais fatores que influenciam a qualidade do produto até o laticínio. $O$ presente trabalho foi realizado na região do Triângulo Mineiro, durante o período de 90 dias, abrangendo uma quantidade de 155 fazendas em 12 municípios. O levantamento de dados nas propriedades foi embasado em um formulário que teve como intuito a obtenção de dados individuais de CCS (Contagem de Células Somáticas), CPP (Contagem Padrão em Placas) e informações da UPL e de seu rebanho (idade dos produtores, área da propriedade, número de vacas lactantes, número de vacas secas, número de animais em recria, produção média diária e manejo). Para a avaliação dos fatores condicionantes na qualidade, foi realizado o acompanhamento desde a coleta do leite nas propriedades até a chegada na indústria. Dentre eles, foram destacados os cuidados durante a coleta, local e condições de refrigeração, presença de resíduos estranhos a composição, aferição da temperatura do leite no tanque e após a chegada no laticínio, armazenamento, refrigeração das amostras até o a empresa e a higienização dos caminhões. Foi realizada a análise estatística descritiva e nas características quantitativas, foi realizada correlação de Pearson, submetidas à análise de variância (ANOVA; $P=0,05$ ). Foi verificado a significância $(p<0,001)$ entre CCS e CPP, além de correlações positivas entre CCS e VS (Vaca Seca) $(r 2=0,139)$ com significância $(p<0,05)$. Foi diagnosticado $83 \%$ de tanques com temperatura desregulada; $96 \%$ das bocas dos caminhões chegaram com leite em temperatura acima do exigido de até $7,0^{\circ} \mathrm{C}$ e quando avaliada a média das temperaturas das amostras apresentou como resultado $4,7 \pm 3,4^{\circ} \mathrm{C}$. Diversas falhas até a chegada do leite na indústria foram diagnosticadas e descritas no presente trabalho, concluindo que há uma grande variação de características entre as UPL's do Triângulo Mineiro em 
relação aos dados qualitativos e quantitativos e que ainda há diversos problemas no transporte que interferem na qualidade do produto final até o laticínio.

Palavras-chave: Instruções normativas, transporte lácteo, capacidade produtiva.

\title{
PRODUCTIVE CHARACTERISTICS OF MPU'S AND CONDITIONING FACTORS OF MILK QUALITY TO INDUSTRY IN THE TRIÂNGULO MINEIRO
}

\begin{abstract}
The objective with this study was to diagnose the characteristics of the Milk Producing Units (UPL's) and other factors that influence the quality of the product up to the industry. The present work was carried out in the Triângulo Mineiro region, during the period of 90 days, covering a number of 155 farms in 12 municipalities. The survey of data on the properties was based on a form that aimed to obtain individual data from CCS (Somatic Cell Count), CPP (Standard Plate Count) and information from the UPL and its herd (age of producers, area of the property, number of lactating cows, number of dry cows, number of animals in breeding, average daily production, management measures). For the evaluation of the conditioning factors in quality, monitoring was carried out from the collection of milk on the properties to the arrival in the industry. Among them, care was taken during collection, location and refrigeration conditions, presence of residues foreign to the composition, checking the temperature of the milk in the tank and after arrival in the industry, storage, refrigeration of the samples to the dairy and the hygiene of the trucks. Descriptive statistical analysis was performed and in the quantitative characteristics, Pearson correlation was performed, submitted to analysis of variance (ANOVA; $P=0.05$ ). Significance ( $p$ $<0.001)$ between CCS and CPP was verified, as well as positive correlations between CCS and VS (Vaca Seca) ( $r 2=0.139)$ with significance $(p<0.05) .83 \%$ of tanks with unregulated temperature were diagnosed; $96 \%$ of the mouths of the trucks arrived with milk at a temperature above the required of up to $7.0^{\circ} \mathrm{C}$ and when evaluated the average temperature of the samples showed as a result $4,7 \pm 3,4^{\circ} \mathrm{C}$. Several failures until the arrival of milk in the industry were diagnosed and described in the present work, concluding that there is a great variation of characteristics among the UPLs of the Triângulo Mineiro in relation to the qualitative and quantitative data and that there are still several problems in the transport that interfere in the quality from the final product to the industry.
\end{abstract}

Keywords: Normative instructions, dairy transport, productive capacity. 


\section{INTRODUÇÃO}

A produção mundial de leite em 2019 atingiu 852 bilhões de litros, sendo que o Brasil ocupa a quinta posição do ranking de maiores produtores, com um volume anual de 34,8 bilhões de litros (ZOCCAL, 2017). O grande crescimento produtivo de leite no Brasil, ocorreu não apenas pelo aumento no número de animais produtores, mas também pelo maior investimento nutricional dos rebanhos, busca constante pela evolução genética, melhorias de manejo sanitário e bem-estar animal. O maior produtor de leite no território nacional é o estado de Minas Gerias, seguido pelos estados do Paraná, Rio Grande do Sul, Goiás e Santa Catarina. Apesar de ser o estado com maior produção, Minas Gerais, ainda apresenta muitas formas de produção pouca tecnologia, levando a uma baixa produtividade por animal média (3011 litros de leite/vaca/ano), destacando a necessidade de evolução produtiva no setor (FAO, 2019; PPM, 2019).

Santos (2014) afirma que a cadeia agroindustrial do leite passou por uma saudável transformação a partir de 2002, quando uma nova legislação brasileira, que regulamenta os critérios mínimos de qualidade e identidade do leite cru, entrou em vigor, por meio da conhecida Instrução Normativa 51/2002. Até 2002, o Brasil não contava com padrões mínimos de contagem de células somáticas (CCS) e de contagem bacteriana total (CBT), que passou a ser determinada por Contagem Padrão em Placas (CPP) para o leite tipo $\mathrm{C}$, assim como não havia exigência legal de resfriamento do leite na fazenda.

Os primeiros requisitos mínimos de qualidade do leite cru foram bastante permissivos, sendo que os primeiros critérios mínimos de qualidade do leite cru, que começaram a vigorar a partir de 01/07/2005 foram de CCS $<1$ milhão cél/ml e CPP $<1$ milhão de Unidades Formadoras de Colônia (UFC/ml). No final de 2011, a IN 51/2002 foi revogada com a publicação da IN 62/2011. A partir de julho/2014, foi prevista uma redução dos limites de CCS para $<500.000$ cél/ml e de CPP para < 300.000 cél/ml (Santos, 2014).

Até então, a última publicação a respeito de legislação sobre as características de leite cru foi a Instrução Normativa ำ 77 , de 26 de novembro de 2018 que entrou em vigor em Maio de 2019 e que diferentemente das anteriores traz descrito penalizações para o produtor e demais envolvidos na 
atividade que se manterem fora dos parâmetros de qualidade de leite exigidos, podendo acarretar na desvinculação do produtor ou transportador, no descumprimento parcial ou total no que está disposto na Instrução Normativa (BRASIL, 2018).

A IN 77/18 afirma que: após a suspensão, o produtor deverá realizar todos os procedimentos necessários para que o leite volte a ter qualidade dentro dos padrões exigidos. Ou seja, verificar a limpeza e funcionamento dos equipamentos de ordenha e tanque, qualidade de água, utilização correta dos produtos químicos, entre outros. Após essas correções uma nova amostra será coletada e enviada ao laboratório e o resultado da CPP estando abaixo de 300 mil UFC/ml a coleta será normalizada (BRASIL, 2018).

Ao ser ordenhado o leite se contamina por bactérias presentes no seio lactífero papilar e chega a ter ao redor de 1.000 a 2.000 bactérias por ml de leite. Se a ordenha for mal-feita a quantidade de bactérias sobe para 25 a 50 mil $\mathrm{UFC} / \mathrm{ml}$ nesse momento. Se esse leite for armazenado a $4^{\circ} \mathrm{C}$, o número pode chegar a $100 \mathrm{mil} \mathrm{UFC/ml} \mathrm{após} 24$ horas. Se, no entanto, a temperatura do tanque for $15^{\circ} \mathrm{C}$, o número de bactérias chegaria a 5 milhões por $\mathrm{ml}$ após 24 horas (MACHADO et al., 2009).

Todos procedimentos inadequados propiciam para 0 aumento de bactérias no leite, prejudicando diretamente na qualidade do produto (SANTOS, 2019). Com o presente trabalho teve-se por objetivo diagnosticar as características das Unidades Produtoras de Leite (UPL's) e demais fatores que influenciam a qualidade do produto até a indústria. 


\section{MATERIAL E MÉTODOS}

O presente estudo foi realizado na região do Triângulo Mineiro, durante 0 período de 90 dias, com início em 29 de julho e término em 25 de outubro de 2019, abrangendo 155 fazendas em 12 municípios, todas produtoras de leite e fornecedoras para duas unidades de captação do Laticínio Jussara, localizadas nas cidades de Frutal e Iturama.

Em um primeiro momento foi realizado o acompanhamento desde a coleta do leite nas propriedades até a chegada no laticínio. Foram observados diversos pontos relevantes para a qualidade do produto, avaliados desde a propriedade produtora até o laticínio que prosseguiria com processamento, dentre eles: partindo de avaliações de manejo de ordenha (como pré e pós dipping) e condições de armazenamento do produto, cuidados durante a coleta de amostras nos tanques de expansão, local e condições de refrigeração nas fazendas, presença de resíduos estranhos a composição natural do leite, aferição da temperatura do leite no tanque de transporte, condições de coleta e armazenamento no caminhão, além da higienização externa e interna dos tanques transportadores.

Os dados foram coletados através com o auxílio da plataforma Excel, em dois momentos distintos, em que um foi destinado a reunião de dados envolvendo as características de produção e transporte do leite, e o segundo foi destinado a coletar de informações sobre o perfil dos produtores e de suas propriedades. Os resultados da pesquisa organizados por técnicos responsáveis, encaminhados para a central de dados da Empresa Companhia do Leite, responsável pela reunião das informações, a pedido do Laticínio Jussara.

Para análise da qualidade do leite no tanque de expansão das propriedades rurais foi coletado uma amostra, a qual foi encaminhada para a Clínica do Leite - Laboratório credenciado ao Ministério da Agricultura (Tabela 1).

Foi esboçado o valor percentual de falhas nos processos de manejo do leite, desde a fazenda até o laticínio na Tabela 2. Foi apresentada na Tabela 3, a análise estatística dos dados qualitativos, das características das propriedades 
e dos produtores, sendo expostos os valores de média e desvio padrão das características avaliadas. Foi realizada a correlação de Pearson entre as variáveis, com nível de significância de $5 \%(p=0,05)$, sendo em seguida, realizada a submissão dos dados a análise de variância (ANOVA).

Tabela 1. Métodos utilizados pela Rede Brasileira de Laboratórios de Controle da Qualidade do Leite (RBQL).

Table 1. Methods used by the Brazilian Network of Milk Quality Control Laboratories (RBQL).

\begin{tabular}{|c|c|c|}
\hline Análise & Unidade & Método \\
\hline $\begin{array}{l}\text { Teor de sólidos totais } \\
\text { (RBQL) }\end{array}$ & $\mathrm{g} / 100 \mathrm{~g}$ & $\begin{array}{l}\text { Método ISO } 9622 \text { / IDF } 141 \text { ancorado por } \\
\text { calibração ao método ISO } 6731 \text { / IDF } 021 \text { (Método } \\
\text { de referência). }\end{array}$ \\
\hline $\begin{array}{l}\text { Teor de sólidos não } \\
\text { gordurosos (RBQL) }\end{array}$ & $\mathrm{g} / 100 \mathrm{~g}$ & $\begin{array}{l}\text { Método ISO } 9622 \text { / IDF } 141 \text { ancorado por } \\
\text { calibração aos métodos IDF } 001 \text { / ISSO } 1211 \\
\text { (método de referência) e IDF } 021 \text { / ISO } 6731 \\
\text { (método de referência). }\end{array}$ \\
\hline $\begin{array}{l}\text { Teor de lactose } \\
\text { anidra (RBQL) }\end{array}$ & $\mathrm{g} / 100 \mathrm{~g}$ & $\begin{array}{l}\text { Método ISO } 9622 \text { / IDF } 141 \text { ancorado por } \\
\text { calibração ao método ISO } 22662 \text { / IDF } 198 \text { (método } \\
\text { de referência). }\end{array}$ \\
\hline $\begin{array}{l}\text { Teor de proteína total } \\
\text { (RBQL) }\end{array}$ & $\mathrm{g} / 100 \mathrm{~g}$ & $\begin{array}{l}\text { Método ISO } 9622 \text { / IDF } 141 \text { ancorado por } \\
\text { calibração ao método ISO } 8968-1 \text { / IDF 20-1 } \\
\text { (método de referência). }\end{array}$ \\
\hline $\begin{array}{l}\text { Contagem de células } \\
\text { somáticas (RBQL) }\end{array}$ & $\begin{array}{l}\text { Células somáticas por } \\
\text { mililitro }(\mathrm{CS} / \mathrm{ml})\end{array}$ & $\begin{array}{l}\text { Método citométrico em fluxo segundo ISO 13366-2 } \\
\text { / IDF 148-2 ancorado por calibração ao método } \\
\text { ISO 13366-1 / IDF 148-1 (Método de referência). }\end{array}$ \\
\hline $\begin{array}{l}\text { Contagem Padrão em } \\
\text { Placas (RBQL) }\end{array}$ & $\begin{array}{l}\text { Unidades formadoras de } \\
\text { colônias por mililitro } \\
\text { (UFC/ml) }\end{array}$ & $\begin{array}{l}\text { Método citométrico em fluxo com conversão para a } \\
\text { contagem padrão em placas ancorada ao método } \\
\text { de referência ISO 4833-1 segundo norma ISO } \\
21187 \text { / IDF } 196 \text {. }\end{array}$ \\
\hline
\end{tabular}

\section{RESULTADOS}

Tabela 2. Falhas diagnosticadas desde a coleta de leite na UPL até o laticínio.

Table 2. Failures diagnosed from milk collection at the UPL to the dairy.

\begin{tabular}{lcc}
\hline Falhas diagnosticadas: & $\begin{array}{c}\text { Total de } \\
\text { observações }\end{array}$ & $\begin{array}{c}\text { Valores } \\
\text { observados }\end{array}$ \\
\hline Leite no Mangote (\% dos caminhões) & 13 & $10(76,9 \%)$ \\
Falhas na limpeza manual & 13 & $2(15,4 \%)$ \\
Tubulações com sujidades & 13 & $3(23,1 \%)$ \\
Presença de manchas internas no mangote & 13 & $1(7,7 \%)$ \\
Demora no descarregamento do caminhão $(>120$ minutos) & 13 & $7(53,8 \%)$ \\
Coleta de leite acima do ideal na propriedade $\left(>4,0^{\circ} \mathrm{C}\right)$ & 155 & $98(63,2 \%)$ \\
Coleta de leite congelado na propriedade & 155 & $6(3,9 \%)$ \\
Uso de objetos no agitador & 155 & $6(3,9 \%)$ \\
Falhas na limpeza da ordenha e tanques & 155 & $82(52,9 \%)$
\end{tabular}


Tanques em condições inadequadas (local aberto; acesso de outros animais; manchas na parte interna; fezes de aves na parte externa da tampa)

Legenda: Leite no mangote - leite residual da tubulação de coleta acoplado ao caminhão de transporte; Falha na limpeza manual - do caminhão, tanque e/ou utensílios de carga e descarga; Tubulação com sujidades - mangote e tubulação externa e interna do caminhão de transporte; Uso de objetos no agitador - fixação de objetos ao agitador dos tanques de expansão, com objetivo de promover o movimento do leite em casos de baixo volume do produto dentro do tanque.

Tabela 3. Características avaliadas dentro da UPL. Table 3. Characteristics evaluated within UPL.

\begin{tabular}{cccccc}
\hline Característica & No de Obs. & Mínimo & Máximo & Média & DP \\
\hline Idade & 155 & 24,0 & 88,0 & 54,2 & 13,5 \\
Área & 155 & 4,8 & 983,0 & 114,2 & 152,4 \\
VL & 155 & 3,0 & 90,0 & 23,2 & 13,7 \\
VS & 155 & 1,0 & 130,0 & 18,5 & 16,6 \\
Recria & 155 & 0,0 & 500,0 & 66,0 & 83,8 \\
Produção diária & 155 & 20,0 & 750,0 & 180,8 & 158,5 \\
CPP & 143 & 2,0 & 3949,0 & 264,3 & 596,8 \\
CCS & 143 & 26,0 & 5353,0 & 581,2 & 693,5 \\
\hline
\end{tabular}

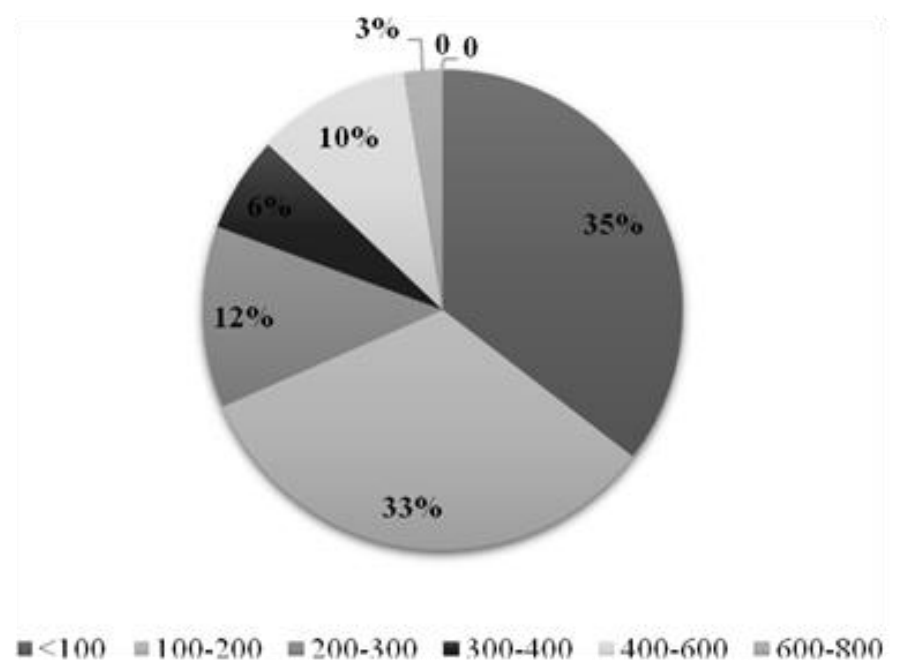

Figura 1. Distribuição da produção média diária de leite em litros.

Figure 1. Distribution of average daily milk production in liters. 
Tabela 4. Características avaliadas dentro da UPL. Table 4. Characteristics evaluated within UPL.

\begin{tabular}{|c|c|c|c|c|c|c|c|c|c|}
\hline & & Idade & Área & VL & VS & Recria & $\begin{array}{l}\text { Produção } \\
\text { diária }\end{array}$ & CPP & ccs \\
\hline \multirow{8}{*}{ 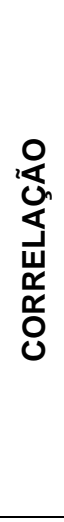 } & Idade & 1,000 & & & & & & & \\
\hline & Área & 0,280 & 1,000 & & & & & & \\
\hline & VL & 0,126 & 0,148 & 1,000 & & & & & \\
\hline & VS & 0,271 & 0,253 & 0,518 & 1,000 & & & & \\
\hline & Recria & 0,249 & 0,478 & 0,288 & 0,329 & 1,000 & & & \\
\hline & $\begin{array}{l}\text { Produção } \\
\text { diária }\end{array}$ & $-0,015$ & $-0,040$ & 0,788 & 0,264 & 0,091 & 1,000 & & \\
\hline & CPP & $-0,017$ & $-0,097$ & 0,073 & 0,102 & $-0,062$ & 0,115 & 1,000 & \\
\hline & ccs & 0,025 & $-0,093$ & 0,212 & 0,139 & 0,028 & 0,269 & 0,393 & 1,000 \\
\hline \multirow{8}{*}{ 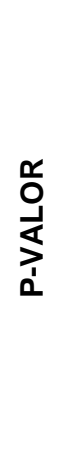 } & Idade & & & & & & & & \\
\hline & Área & 0,000 & & & & & & & \\
\hline & VL & 0,067 & & & & & & & \\
\hline & vs & 0,001 & 0,001 & 0,000 & & & & & \\
\hline & Recria & 0,001 & 0,000 & 0,000 & 0,000 & & & & \\
\hline & $\begin{array}{l}\text { Produção } \\
\text { diária }\end{array}$ & 0,430 & 0,318 & 0,000 & 0,001 & 0,139 & & & \\
\hline & CPP & 0,419 & 0,125 & 0,192 & 0,112 & 0,229 & 0,086 & & \\
\hline & ccs & 0,383 & 0,134 & 0,005 & 0,049 & 0,369 & 0,001 & 0,000 & \\
\hline
\end{tabular}

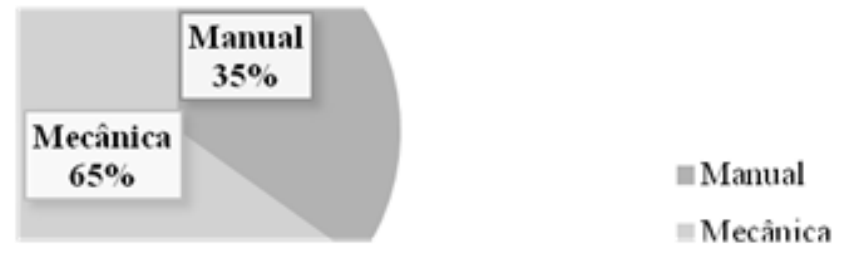

Figura 2. Tipo de ordenha realizadas nas propriedades leiteiras avaliadas.

Figure 2. Type of milking performed on the evaluated dairy farms. 


\section{DISCUSSÃO}

De um total de 155 tanques de expansão, observou-se que 129 (83,2\%) estavam desregulados, com relação a mantença de temperatura ideal para conservação do leite cru (ideal $\leq 4{ }^{\circ} \mathrm{C}$ ). $\mathrm{Na}$ avaliação geral dos tanques de expansão, a desregulagem partia de $0,3^{\circ} \mathrm{C}$ acima do valor recomendado pelas normativas, ou seja, das propriedades avaliadas e que tinha aumento de temperatura do produto no momento de coleta, a que apresentava temperatura mais próxima do almejado estava com $4,3{ }^{\circ} \mathrm{C}$. Este fato apresenta grande influência sobre a qualidade do produto comercializado com o laticínio, sendo observado um crescimento de bactérias presentes nas amostras aumentando os resultados da CPP. Segundo Tebaldi et al. (2008), temperaturas acima do recomendado podem predispor a multiplicação de microrganismos que podem produzir enzimas extracelulares como lipases e proteases acarretam em uma maior deterioração do leite cru.

Em relação aos cuidados durante a coleta não foi observado nenhum erro dos transportadores, mostrando que os mesmos estão capacitados para tais coletas, não tendo assim interferência nos resultados das análises. Porém, quando se avaliou a média das temperaturas das amostras de leite que são encaminhadas a avaliação de qualidade, teve-se como resultado $4,7 \pm 3,4^{\circ} \mathrm{C}$, sendo que a exigência descrita na Instrução Normativa 77 é de até $7,0^{\circ} \mathrm{C}$. Assim, observa-se que na avaliação do desvio padrão, ocorre intervalor de $1,1^{\circ} \mathrm{C}$ acima do ideal, demonstrando temperaturas elevadas que podem interferir para 0 aumento de bactérias presentes nas amostras, aumentando os resultados da CPP.

$\mathrm{Na}$ atual Instrução Normativa (IN 77), tem-se a exigência de que a temperatura do leite nos caminhões não ultrapasse, em condições normais, a temperatura de $7,0^{\circ} \mathrm{C}$ (BRASIL, 2018). O caminhão é dividido em compartimentos, cada um com uma boca específica, para melhor armazenamento durante $\mathrm{o}$ transporte do leite. No acompanhamento das temperaturas de todas as bocas que chegaram com leite ( 25 bocas), observouse que apenas uma chegou com temperatura ideal $\left(6,8^{\circ} \mathrm{C}\right)$, ou seja, $96,0 \%$ chegaram acima da temperatura exigida de até $7,0^{\circ} \mathrm{C}$. Nessas circunstâncias, 
antes que o leite seja processado pelo laticínio, amostras do produto são coletadas e passam por análises de qualidade e viabilidade do produto, sendo iniciado o processamento somente após comprovação da segurança para uso e consumo deste leite.

Outras falhas desde a coleta na UPL até a limpeza do caminhão no laticínio foram diagnosticadas e estão descritas na Tabela 2.

Baseado na Tabela 3, foi observado que a idade média dos produtores se encontra em torno dos 54 anos e que a área média em hectares das UPL's é de $114 \pm 152$. Assim, caracteriza-se propriedades médias com produtores em idade avançada em relação a vida profissional, o que mostra a falta de jovens na atividade e também falhas na sucessão familiar. De acordo com Breitenbach et al. (2017) e Breitenbach et al. (2019), as dificuldades de sucessão familiar e atuação de jovens na produção, ocorrem, não apenas na produção de leite brasileira, mas também em todos os setores agropecuários. Na produção leiteira, especificamente, tal fato se justifica pelo árduo trabalho diário, a constante necessidade de investimento, cansativa carga horária, complexidade das atividades e oscilações constantes de faturamento. Estes fatores se intensificam nos casos de pequenas produções, que são responsáveis pela maior parte da produção nacional.

Quando observado VL e VS na propriedade obteve-se a quantidade média de 23 e 18 animais respectivamente, o que mostra uma baixa lotação por hectare ( 0,2 vacas lactantes/há, sendo o cálculo embasado na média da área das propriedades, dividido pelo número de vacas em lactação $-114,2 / 23,2=$ 4,92 ha/vaca ou 0,2 vaca/ha), visto que segundo Rabelo (2017) em uma pastagem tropical com manejo intensivo essa lotação deve ser acima de 5 vacas/ha. $\mathrm{O}$ avanço produtivo das propriedades depende diretamente da junção de fatores nutricionais, sanitários e reprodutivos dos rebanhos, que apesar de serem diretrizes já bastante discutidas, ainda sofrem reduzida implantação em propriedades de baixa produção, mesmo se tratando de Minas Gerais, o estado com maior produtividade leiteira nacional. Muitas vezes, este fato ocorre pela reduzida abertura de produtores de leite pequenos, que apesar de serem grande maioria, ainda insistem em manter um tipo de produção tradicional, sendo as fazendas vistas como empreendimento pouco lucrativo e eficiente (Neto, et al. 2018). 
A produção de leite variou de 20 a 750 litros diários entre as UPL's visitadas, tendo um valor médio de 180 litros produzidos por dia, caracterizando uma média de 7,8 litros por animal. Com isso tem-se a produção média de 576 litros/ha/ano. A distribuição média diária de todas as UPL's pode ser observada no Gráfico 1. Existe um grande número de pequenas propriedades leiteiras no Brasil, sendo correlacionado ao baixo nível de tecnificação envolvendo na atividade, grande prevalência de pequenas propriedades com mão de obra familiar e a reduzida busca por melhoria de produtividade, levam ao uma reduzida produção de litros de leite por ha/ano (VILELA et al. 2017).

Foi observado valores de CPP de até $3949 \mathrm{mil} \mathrm{UFC/ml} \mathrm{e} \mathrm{CCS} \mathrm{de} \mathrm{até} 5353$ mil cél/ml. Foi obtido 31 UPL's (20\%) com valores de CPP acima de $300 \mathrm{mil}$ $\mathrm{UFC} / \mathrm{ml}, 8 \%$ não haviam tais análises (por serem novos produtores) e $72 \%$ se encontraram com resultados dentro do exigido. Já em relação a CSS obteve-se $34 \%$ de UPL's com valores acima de $500 \mathrm{mil}$ UFC $/ \mathrm{ml}, 8 \%$ não havia tais análises (por serem novos produtores) e $58 \%$ se encontraram com resultados dentro do exigido. Altos valores de CPP podem ser observados em locais que possuem diversas falhas de manejo na limpeza de equipamentos, associados ou não com falta de manutenções no tanque de expansão, propiciando no aumento de bactérias presentes no leite. Já altos valores de CCS são observados em rebanhos com maior incidência de casos de mastite, devido a ambientes com alta contaminação e não realização das corretas práticas no manejo de ordenha.

Teixeira Júnior et al. (2015) destaca em seu trabalho que a busca por constantes melhorias ou pelo menos manutenção de boas condutas produtivas, acarretam uma melhor qualidade dos produtos produzidos por propriedades leiteiras, levando a um diferencial da remuneração, correlacionada a bonificações pelos laticínios, envolvidos principalmente no cumprimento das diretrizes das IN 77 / 2018. Estas iniciativas visam favorecer os resultados econômico-financeiros e levam a uma maior rentabilidade dos sistemas de produção.

Valling et al. (2009) afirmam que a adoção de técnicas corretas de manejo de ordenha pode reduzir em $55,65 \%$ a contagem de células somáticas e em 93,95\% a contagem bacteriana total, que corrobora assim com Bozo et al. (2013) que realizaram um trabalho com o objetivo de adequar a qualidade do leite cru refrigerado de cinco propriedades leiteiras no estado do Paraná. A média de CPP 
era de $1,36 \times 106 \mathrm{UFC} / \mathrm{ml}$ e de CCS de $1,87 \times 106 \mathrm{cel} / \mathrm{ml}$. Após a implantação de boas práticas de ordenha e adoção de recomendações quanto ao tratamento de mastites e à manutenção e higienização dos equipamentos de ordenha houve uma redução média de $93,4 \%$ na CPP e $74,3 \%$ na CCS.

Foi verificado a significância $(p<0,001)$ entre CCS e CPP ( $r 2=0,393)$. Esse fato mostra a relação positiva em que propriedades com maior valor de CCS apresentam também maiores valores de CPP. Segundo Santos e Fonseca (2019) as infecções intramamárias podem contribuir de forma significativa para o aumento da CPP. Para os mesmos autores essa contaminação depende do tipo de microrganismo causador da infecção, do estágio e gravidade da mastite e da prevalência de vacas infectadas no rebanho.

Santos e Fonseca (2019) citam que o principal grupo de agentes causadores de mastite associados ao aumento de CPP do leite é Streptococcus spp., sendo que dentre as espécies mais importantes destacam-se Streptococcus agalactiae e Streptococcus uberis. Por outro lado, infecções causadas por Staphylococcus não estão associadas com alta de CPP. Assim sendo há necessidade da realização de ajustes no manejo tanto para controle de CPP quanto de CSS.

No presente trabalho foi diagnosticado que 11 UPL's $(7,1 \%)$ realizam o manejo de pré-dipping e que apenas 4 UPL's $(2,6 \%)$ realizam o manejo de pósdipping. Zucali et al. (2011) observaram que operações de rotina na ordenha, como realização de pré-dipping e pós-dipping afetaram fortemente as contagens bacterianas do leite, de forma que as propriedades que realizavam estas operações apresentaram menor contaminação dos tetos e menores contagens de bactérias psicrotróficas, termodúricas, coliformes e células somáticas do que as propriedades que não realizavam estas operações. Elmoslemany et al. (2010) também observaram que as rotinas antes da ordenha são importantes na redução da contagem bacteriana do leite, especialmente o pré-dipping e a secagem dos tetos.

Também se verificou correlações positivas entre CCS e VS ( $\mathrm{r} 2=0,139)$ com significância $(p<0,05)$. Este fato pode apresentar intima correlação com alguns valores altos de CCS em alguns rebanhos, possivelmente tendo como justificativa a secagem de vacas para tratamento de infecções da glândula mamária, ou seja, vacas fora de lactação devido a maior incidência de casos de 
mastites em alguns rebanhos. Segundo Santos (2006) a adoção de programas para o controle da mastite teve grande impacto na redução da doença em diversos países do mundo, cujas medidas mais usadas atualmente são as práticas de desinfecção dos tetos antes e após-ordenha, e o uso de antibioticoterapia na secagem dos animais.

Quando avaliado CCS e produção diária foi observado correlações positivas $(r 2=0,269)$, podendo demonstrar que muitas propriedades apresentam maior foco em produção de volume sem se preocupar com as questões de qualidade do produto produzido. Apesar de tudo, isso não se aplica a todas as UPL's, sendo restrito apenas a algumas unidades.

$\mathrm{Na}$ tabela 2 foi possível observar que em 52,9\% das propriedades há falhas na limpeza da ordenha e dos tanques que interferem diretamente para 0 aumento de CPP, podendo esses fatos terem correlação direta com baixa capacitação e noções de higiene de produtores e colaboradores. De acordo com Vallin et al. (2009), qualidades de leite baixas tem correlações diretas como deficiências, principalmente, no manejo e higiene da ordenha, grande número de animais com mastite (principalmente subclínica), reparação e limpeza inadequadas dos equipamentos, conservação do produto de forma ruim e baixa capacitação e dedicação da mão de obra.

Das 31 UPL's com altos valores de CPP foi diagnosticado que 27 delas (87\%) são de ordenha mecânica e apenas quatro (13\%) são de ordenha manual. Apesar de $87 \%$ das UPL's apresentarem de ordenha mecânica foi possível observar, em algumas propriedades falhas na limpeza de teteiras, copos coletores e mangueiras. Já em algumas propriedades de ordenha manual, notou-se falhas na limpeza e falta de manutenções nos tanques de refrigeração. Com tudo, essas avaliações mostraram que a realização de ordenha mecânica não significa, necessariamente, uma ordenha limpa, e que uma ordenha manual, não é sinônimo, de ordenha pouco higiênica.

Nos trabalhos de Werncke e colaboradores (2016), realizado na região do Vale do Braço do Norte, sul de Santa Catarina, foi observado que havia ordenha mecânica com balde ao pé em $47 \%$ das propriedades, e a ordenha canalizada ou com transferidor de leite em $51 \%$; apenas um produtor realizava ordenha manual, que difere do presente trabalho, onde 54 propriedades (35\%) realizam ordenha manual. 
Ainda segundo os mesmos autores o armazenamento e o resfriamento do leite são realizados em tanques de expansão (82\%) ou em tanques de imersão (18\% das propriedades), porém a realidade da região do Triângulo Mineiro é diferente, onde $100 \%$ dos tanques são de expansão, não havendo tanque de imersão.

Yuen et al. (2012) citaram que maioria dos produtores ainda realiza práticas de higiene de ordenha e de gestão agrícolas ineficazes, resultando em leite de baixa qualidade, com grandes perdas econômicas para a indústria. Almeida (2013) afirma que é preciso e possível melhorar a qualidade do leite e produtos lácteos produzidos no Brasil, no entanto esta melhoria depende do envolvimento de todos que fazem parte da cadeia produtiva do leite, sejam eles produtores, ordenhadores, transportadores, indústrias, técnicos ou consumidores.

\section{CONCLUSÃO}

Conclui-se que há uma grande variação de características entre as UPL's do Triângulo Mineiro em relação aos dados qualitativos e quantitativos, verificando deficiências no manejo produtivo que prejudicam a qualidade do leite. Em relação ao transporte até o laticínio, nota-se problemas que interferem na qualidade do produto final, havendo assim a necessidade de correções tantos nas UPL's (com o fornecimento de um produto em temperatura adequada para a coleta), quanto nos laticínios, tomando medidas de transporte e velocidade de processamento mais eficientes. 


\section{REFERÊNCIAS}

ALMEIDA, T. V. de; Parâmetros de qualidade do leite cru bovino: Contagem Bacteriana Total e Contagem de Células Somáticas. Universidade Federal de Goiás Escola de Veterinária e Zootecnia Programa de Pós-Graduação em Ciência Animal. Goiânia, 2013. Disponível em: $<$ https://files.cercomp.ufg.br/weby/up/67/0/2013_Thamara_Venancio_Seminario 1corrig.pdf> Acesso em: 12/11/2019.

BOZO, G. A.; ALEGRO, L. C. A.; SILVA, L. C.; SANTANA, E. H. W.; OKANO, W.; SILVA, L. C. C. Adequação da contagem de células somáticas e da contagem bacteriana total em leite cru refrigerado aos parâmetros da legislação. Arquivo Brasileiro de Medicina Veterinária e Zootecnia, v. 65, n. 2, p. 589594, 2013. DOI: https://doi.org/10.1590/S0102-09352013000200040

BRASIL, Ministério da Agricultura, Pecuária e Abastecimento. Instrução Normativa ํㅜ 76, de 26 de novembro de 2018. Regulamentos Técnicos que fixam a identidade e as características de qualidade que deve apresentar o leite cru refrigerado, o leite pasteurizado e o leite pasteurizado tipo A. Diário Oficial da União, Brasília, 30 nov. 2018, seção 1, p.9-10.

BREITENBACH, R., CORAZZA, G. Perspectiva de permanência no campo: Estudo dos jovens rurais de Alto Alegre, Rio Grande do Sul/Brasil. Revista ESPACIOS, v. 38, n 29, p. 9, 2017.

BREITENBACH, R., MAZOCCO, C. C., CORAZZA, G. Estímulo à sucessão familiar na bovinocultura de leite: relato de experiência. Revista Brasileira de Extensão Universitária, v. $10, \mathrm{n}^{\circ} 1, \quad$ p. $25-33,2019 . \quad$ DOI: https://doi.org/10.24317/2358-0399.2019v10i1.10555.

CARVALHO, G. R.; ROCHA, D. T. da; O leite em 2018 e perspectivas para 2019. Anuário Leite 2019. pg: 10 - 12. Embrapa Gado de Leite, Juiz de Fora MG, 2019. 
ELMOSLEMANY, A. M.; KEEFE, G. P.; DOHOO, I. R.; WICHTEL, J. J.; STRYHN, H.; DINGWELL, R. T. The association between bulk tank milk analysis for raw milk quality and on-farm management practices. Preventive Veterinary Medicine, v. $\quad 95, \quad$ p. $\quad 32-40, \quad 2010 . \quad$ DOI: https://doi.org/10.1016/j.prevetmed.2010.03.007.

FAO. Dairy Market Review. Food and Agriculture Organization, 2019. Disponível em: Dairy Market Review - Overview of global dairy market developments in 2019 (fao.org). Acesso em: 15 de novembro de 2020.

JAMAS, L. T.; SALINA, A.; ROSSI, R.; MENOZZI, B. D.; LANGONI, H. Parâmetros de qualidade do leite bovino em propriedades de agricultura familiar. Pesq. Vet. Bras. v. 38, n. 4, p. 573-578. Faculdade de Medicina Veterinária e Zootecnia (FMVZ), Botucatu, SP., 2018. Disponível em: < http://www.scielo.br/pdf/pvb/v38n4/1678-5150-pvb-38-04-573.pdf> Acesso em: 16/09/2019. DOI: https://doi.org/10.1590/1678-5150-pvb-5372

MACHADO, P. F., CASSOLI, L. D., SILVA, A. L. O que é leite de qualidade. Revista Mundo do Leite, v. 7, n. 35, p. 22-26, fev-mar, 2009.

NETO, A. C., VIEIRA, G. H. S., HADDADE, I. R., ROSADO, T. L., MELLO, B. L. B. Aplicação de novas tecnologias na bovinocultura leiteira. Incaper em Revista, v. 9, p. 51-65, 2018.

PPM. Produção da Pecuária Municipal 2019. IBGE, Rio de Janeiro, V. 47, p. 18, 2019.

RABELO, E. Formulação de dieta para bovinos de leite. Pós-graduação nutrição de bovinos leiteiros pela Rehagro -UBERLÂNDIA/MG. 2017.

SANTOS, M. V. Avanços no controle da saúde da glândula mamária. Qualileite/FMVZ-USP. Pirassununga-SP, Revista Eletrônica MilkPoint. 2006. Disponível em: <https://www.milkpoint.com.br/colunas/marco-veiga-dos- 
santos/avancos-no-controle-da-saude-da-glandula-mamaria-29294n.aspx> Acesso em 21 nov. 2019.

SANTOS, M. V. dos; FONSECA, L. F. L.da; Controle da Mastite e Qualidade do leite - Desafios e Soluções. 1를 Edição. Edição dos autores, Pirassununga - SP. p. 281. 2019.

SANTOS, M. V. Padrões mínimos de qualidade do leite: é necessária uma nova revisão da IN 62?Qualileite/FMVZ-USP. Pirassununga-SP, Revista Eletrônica MilkPoint. 2014.2 Disponível em: $<$ https://www.milkpoint.com.br/colunas/marco-veiga-dos-santos/padroesminimos-de-qualidade-do-leite-e-necessaria-uma-nova-revisao-da-in-62205597n.aspx> Acesso em 16 set. 2019.

TEBALDI, V. M. R., OLIVEIRA, T. L. C., BOARI, C. A., PICCOLI, R. H. Isolation of coliforms, staphylococci, and enterococci in raw milk from communitarian expansion refrigeration tanks: identification, lipolytic and proteolytic action. Food Science and Technology. V. 28, $n^{\circ}$ 3, 2008.

TEIXEIRA JÚNIOR, F. E. P., LOPES, M. A., RUAS, J. R. M. Efeito do pagamento por qualidade do leite na rentabilidade da atividade leiteira. Revista do Instituto de Laticínios Cândido Tostes, Juiz de Fora, v. 70, n. 1, p. 24-34, 2015. DOI: 10.14295/2238-6416.v70i1.375.

VALLING, V. M.; BELOTI, V.; BATTAGLINI, A. P. P. Melhoria da qualidade do leite a partir da implantação de boas práticas de higiene na ordenha em 19 municípios da região central do Paraná. Semina, v.30, p.181-188, 2009. DOI: https://doi.org/10.5433/1679-0359.2009v30n1p181

VILELA, D.; RESENDE, J. C. D.; LEITE, J. B.; ALVES, E. A evolução do leite no Brasil em cinco décadas. Revista de Política Agrícola, v. 26, n. 1, p. 5-24, 2017.

WERNCKE, D.; GABBI, A. M.; ABREU, A. S.;FELIPUS,N. C.; MACHADO, N. L.;CARDOSO, L. L.;SCHMID, F. A.; ALESSIO, D. R. M.; FISCHER, 
V.;THALER NETO, A.; Qualidade do leite e perfil das propriedades leiteiras no sul de Santa Catarina: abordagem multivariada. Arq. Bras. Med. Vet. Zootec. v.68, n.2, Belo Horizonte mar./abr. $2016 . \quad$ DOI: https://doi.org/10.1590/1678-4162-8396

YUEN, S. K.; YEE, C. F.; YIN, F. H. Microbiological Quality and the impact of hygienic practices on the raw milk obtained from the small-scale dairy farmers in Sabah, Malaysia. Int. J. Agr. Food Sci. v.2, p.55-59, 2012.

ZOCCAL, R. Ações e tendências nas indústrias de laticínios. Balde Branco, São Paulo, v. 52, n. 632, p. 8-9, 20172.

ZUCALI, M.; BAVA, L.; TAMBURINI, A.; BRASCA, M.; VANONI, L.; SANDRUCCI, A. Effects of season, milking routine and cow cleanliness on bacterial and somatic cell counts of bulk tank milk. Journal of Dairy Research, v. 78, p. 436-441, 2011. DOI: https://doi.org/10.1017/S0022029911000598. 